\title{
Communicating About Alcohol Consumption to Nonharmful Drinkers with Hepatitis C: Patient and Provider Perspectives
}

\author{
Carol E. Blixen, PhD, RN ${ }^{1,2}$, Noah J. Webster, $M A^{2}$, Andrew J. Hund, $M A^{2}$, Adam T. Perzynski, MA ${ }^{2}$, \\ Stephanie W. Kanuch, MEd' Eleanor Palo Stoller, PhD ${ }^{3}$, Richard A. McCormick, PhD², \\ and Neal V. Dawson, MD
}

${ }^{1}$ Center for Health Care Research and Policy, Case Western Reserve University at MetroHealth Medical Center, Cleveland, OH, USA; ${ }^{2}$ Case Western Reserve University, Cleveland, OH, USA; ${ }^{3}$ Wake Forest University, Winston-Salem, NC, USA; ${ }^{4}$ Department of Medicine, Case Western Reserve University School of Medicine and Center for Health Care Research and Policy, MetroHealth Medical Center, Cleveland, OH, USA.

BACKGROUND: Abstaining from alcohol consumption is generally recommended for patients with Hepatitis $\mathrm{C}$ (HCV). However, mixed research findings coupled with a lack of consistent guidelines on alcohol consumption and HCV may influence what healthcare providers tell their HCV patients about drinking. This may be more problematic when advising nonharmful drinkers with $\mathrm{HCV}$, a population for whom consumption would not be a problem in the absence of their HCV diagnosis.

OBJECTIVE: This study explores what healthcare providers advise their HCV patients who are drinking alcohol at nonharmful levels about alcohol use and what these patients actually hear.

DESIGN: We conducted separate focus groups and interviews about alcohol use and HCV with nonharmful drinkers with HCV $(N=50)$ and healthcare providers $(N=$ 14) at a metropolitan teaching hospital. All focus groups and interviews were audio-taped, transcribed, and analyzed using NVivo, a qualitative data management and analysis program.

RESULTS: We found similar themes about HCV and alcohol consumption (stop completely, occasional drink is ok, cut down, and provision of mixed/ambiguous messages), reported by both providers and patients. Patient respondents who reported hearing "stop completely" were more likely to have had their last medical visit at the gastroenterology (GI) clinic as opposed to the internal medicine (IM) clinic. Furthermore, IM providers were more likely to give their recommendations in "medical language" than were GI providers.

CONCLUSIONS: To make the best health-related decisions about their disease, HCV patients need consistent information about alcohol consumption. Departments of Internal Medicine can increase provider knowledge about HCV and alcohol use by providing more education and training on $\mathrm{HCV}$.

The online version of the article can be found at http://dx.doi.org/ 10.1007/s11606-007-0483-y.

Received April 30, 2007

Revised August 29, 2007

Accepted November 27, 2007

Published online June 18, 2008
KEY WORDS: Hepatitis C; alcohol consumption; patient-provider communication.

J Gen Intern Med 23(8):1290-5

DOI: $10.1007 / \mathrm{s} 11606-008-0649-2$

(C) Society of General Internal Medicine 2008

\section{BACKGROUND AND OBJECTIVE}

Reducing consumption of alcohol is recommended for patients with the hepatitis C virus (HCV). ${ }^{1-6}$ However, there are conflicting medical opinions and guidelines on what level of alcohol use is detrimental for patients with HCV. ${ }^{7}$ While the Journal of the American Medical Association recommends that patients with $\mathrm{HCV}$ avoid alcohol, ${ }^{1}$ the consensus from the National Institutes of Health's most recent conference on the topic was that "safe levels of alcohol consumption are still unclear, and even moderate levels of consumption may accelerate disease progression in some patients". ${ }^{2}$

These conflicting opinions and guidelines on the subject of alcohol consumption may be evidence of the lack of consistent research findings about alcohol and $\mathrm{HCV}^{6,7}$ Some studies have found that even at low to moderate levels of consumption, alcohol has been linked to negative HCV prognosis ${ }^{4-6}$ through aggravation of histological lesions 4 and increasing fibrosis ${ }^{5,6}$ which may lead to cirrhosis and/or hepatic cancer/hepatoma. ${ }^{5}$ Other studies have found that lifetime alcohol intake level is more important in terms of disease progression than current drinking level, ${ }^{8}$ while some studies have found no link between excessive drinking and cirrhosis. ${ }^{9,10}$

For patients with HCV, abstaining from alcohol may be particularly challenging. $\mathrm{HCV}$ is generally asymptomatic throughout its course, and the consumption of alcohol in the face of chronic HCV infection does not consistently lead to symptoms. In addition, mixed research findings about suggested levels of alcohol intake can often leave providers with no clear, established, single message about alcohol consumption to pass on to their HCV positive patients. A recent survey of 204 patients with $\mathrm{HCV}$ revealed that 58\% reported being counseled to avoid hepatotoxic medications by their physician, while less than half $(47 \%)$ reported being told to avoid or cut down on alcohol use. ${ }^{11}$

Most research on the topic of patient alcohol consumption has focused on dependent or harmful drinkers who experience major impediments to reduction associated with denial, phys- 
ical dependence, and withdrawal. ${ }^{12}$ In this study, we explored the range of themes and topics surrounding alcohol consumption as they pertain to patients with $\mathrm{HCV}$ who are drinkers at a level that is not dependent, or harmful (recent physical or mental harm from drinking). The inclusion of problem drinkers in our study could confound the effect of advice to reduce consumption since it could occur independent of the presence of HCV or other chronic illnesses. A recent study of nonharmful drinkers with $\mathrm{HCV}$ found that many of these patients "tailor" or modify provider advice to abstain from alcohol to fit within the contextual situations of their lives in the form of cutting down, substituting types of alcohol, or limiting intake to special occasions. ${ }^{13}$

In light of these findings, we report on what nonharmful drinkers with HCV tell us they heard about alcohol consumption during their visits with their health-care providers, as well as on what health-care providers tell us they said to patients about this subject.

\section{DESIGN}

Data. Exploratory qualitative investigation of what healthcare providers advise their HCV patients who are nonharmful drinkers about alcohol use and what these patients report hearing. Data for this investigation were collected as part of a larger NIH funded study, "Alcohol Reduction in Medical Illnesses (ARIMI): HCV as Prototype," whose ultimate goal is to develop and test an instrument that predicts alcohol consumption decisions among nonharmful drinkers diagnosed with HCV.

We collected and analyzed multiple sources of cross-sectional textual data: (1) semi-structured interviews with patients diagnosed with HCV ( $N=34)$; (2) three separate focus groups with patients diagnosed with $\mathrm{HCV}$ (focus group no. 1 with 10 participants, no. 2 with 3 , and no. 3 with 3 for a total $N=16$ ); (3) semi-structured interviews with Gastroenterology (GI) physicians $(N=6)$; (4) a focus group with Internal Medicine (IM) physicians $(N=4)$, and $(5)$ a focus group with nurses from the GI and IM clinics $(N=4)$ for a total sample size of 64 respondents. The study was approved by the Institutional Review Board of MetroHealth Medical Center, Cleveland, Ohio, and all participants in the study provided written informed consent.

Collection of Patient Data. Eligible patient subjects were drinkers who were not classified as dependent, abusing, or harmful drinkers, defined as a score of ten or less on the alcohol use disorders identification test (AUDIT), ${ }^{14}$ an instrument used to assess alcohol intake over the past year. The cutoff on the AUDIT has been validated in medical clinic populations. ${ }^{15}$ The CAGE (cut down, angry, guilty, eye-opener), an assessment of lifetime problem drinking risk with scores ranging from 0 to $4^{16}$ was also administered to all the patients. All patient subjects were recruited according to a sampling grid designed to ensure variability in race/ethnicity and level of alcohol use. As well as measures of alcohol use, the prescreening questionnaire included measures of gender, age, race/ethnicity, and education. Additional information was extracted from patients' electronic medical records including visits to the GI and IM clinics before study participation.
The guiding principle in determining sample size in qualitative research is theoretical saturation which is reached when ongoing data collection no longer yields new information and insights. To obtain theoretical saturation, one samples until no new data emerge. ${ }^{17}$ Thirty-four subjects participated in individual semi-structured interviews which is within the 30-50 respondents recommended as a guideline for reaching theoretical saturation in individual interviewing. ${ }^{18}$ To maximize the range of potential responses, we also conducted three focus groups with 16 participants. The rule of thumb for reaching theoretical saturation in focus groups, is to conduct three groups and then evaluate for theoretical saturation. If theoretical saturation has not occurred after the third group, or if new themes emerge, a fourth focus group is conducted. ${ }^{19}$

All patient interviews $(N=50)$ were conducted with $\mathrm{HCV}$ patients at an urban teaching hospital in Northeast Ohio. Recruitment for the interviews and focus groups was done in person at the GI clinic and at educational sessions for people preparing for HCV treatment. The interview and focus group guides included 12 main questions pertaining to people's knowledge, experience, and management of their HCV infection. Interviewers used both structured probes (included in the interview protocol) and follow-up questions to encourage respondents to elaborate answers, and to explore the context of responses. ${ }^{20,21}$ Questions regarding alcohol use were included in the structured probes. We focused specifically on responses to probes about what they were told by their healthcare providers regarding their disease and alcohol consumption (i.e. "Did the doctors and/or nurses talk to you about drinking alcohol since your diagnosis of HCV?" and "Could you tell me more about that?"). We also probed respondents to determine if and how their providers explained why the issue of alcohol was important in conjunction with HCV (i.e. "Did they explain why those changes were important?" in reference to instructions from providers about changes in drinking behavior). Interviews and focus groups were tape recorded, transcribed verbatim, and lasted from 30 to 90 min depending on the type of interviewing format used, time since diagnosis, and the level of the participant's comfort with verbalizing thoughts and ideas.

Collection of Healthcare Provider Data. Eligible provider subjects were healthcare professionals, working at the same urban teaching hospital from which the patient subjects were recruited. Provider recruitment occurred in sequence. First, providers (both physicians and nurses) working in the IM and GI clinics were sent a letter inviting them to participate in a focus group. Two focus groups were scheduled and completed, the first with four IM physicians, and the second with four nurses. Because GI physicians found it difficult to commit to a 90-min focus group, they received a second mailing asking them to participate in a semi-structured interview at their convenience. Six interviews were scheduled and completed with these physicians for a total sample of 14 providers.

The focus group and interview guide administered to the provider subjects was very similar to the guide used with the patient subjects but the questions reflected upon their own advice to their patients about alcohol consumption and HCV (i.e. "What do you specifically tell your HCV patients who are nonharmful drinkers about alcohol use?") as well as the providers' understanding of their patients' perspectives (i.e., 
"What have your patients who are nonharmful drinkers told you about their understanding of alcohol use and HCV?"). The focus groups and interviews were tape recorded, transcribed verbatim, and lasted from 30 to 120 min depending on the type of format used and practice time pressures.

Analysis. In qualitative research, the data collection, coding, and analysis occur simultaneously rather than sequentially. Emerging insights can be incorporated into later stages of data generation, enhancing the comprehensiveness of the results. ${ }^{22}$ In the present study, patient textual data, which included responses to questions about provider suggestions regarding alcohol use (if it was mentioned at all), were selected from the interview and focus group transcripts and compiled into one document. For the provider data, the entire transcript was used to analyze themes of what the providers reported telling their HCV patients about alcohol.

The next two steps of the qualitative data analysis were applied to both sets of qualitative data (patient and provider responses). Two of the researchers ( $\mathrm{CB}$ and $\mathrm{NW}$ ) began by independently open-coding ${ }^{23}$ the textual data to identify and record general themes and topics that arose. ${ }^{24}$ They then met again to discuss the results of the general coding process and compare lists of themes recorded. Any discrepancies in coding were resolved through discussion. Once there was consensus on the list of general themes/descriptive codes, the two researchers again read through the textual data to elaborate the list of themes and develop sub-categories. At a third meeting, the two researchers discussed the elaborated and refined listing of themes (coding structure). From this discussion, a final list of themes (including sub-categories) and their accompanying mutually exclusive definitions were recorded. This final list of themes was applied to a sample of the data to check for inter-rater reliability, and a Kappa of 0.87 was calculated.

The textual data from the transcripts and the finalized refined list of themes were then imported into NVivo, a qualitative data management program. ${ }^{25}$ Using NVivo, segments of text were highlighted and classified according to the theme(s) illustrated. In this process the themes or codes become "buckets or baskets into which the segments of text are placed." ${ }^{26}$ This process was repeated again for the provider textual data.

\section{RESULTS}

Characteristics of the Sample. Patient interview respondents and focus group participants ranged from 35 to 74 years of age (mean=48.4; $\mathrm{SD}=6.6$ ). Thirty-six percent were female, and the mean years of education was 12.3 ( $\mathrm{SD}=2.1$; range: 5 to 16$)$. There were $36 \%$ who identified themselves as African American, 20\% as Hispanic, and $44 \%$ as White. The mean AUDIT score for the sample was $3.7(\mathrm{SD}=3.6)$, with $27 \%$ having a score of 0 (no drinks of alcohol over the past year), $46 \%$ with a score in the range of 1 to 7 , and $27 \% 8$ to 10 . The median CAGE score was 2 , with $17 \%$ having a score of $0,26 \% 1,13 \%$ 2 , and $45 \%$ with a score of 3 or higher.

Among the patients, $36 \%(N=18)$ had been seen by a provider only at the GI clinic, $2 \%(N=1)$ only at the IM clinic,
$40 \%(N=20)$ at both clinics, and $22 \%(N=11)$ at neither clinic before study participation. Lastly, $50 \%(N=25)$ of the patients had their most recent medical visit before study participation at the GI Clinic (mean number of days from last GI Clinic visit to study participation $=107.2 ; \mathrm{SD}=147.6$; range: 0 to 705.0 ) and $28 \%(N=14)$ at the IM Clinic (mean number of days from IM clinic visit to study participation $=47.0$; $\mathrm{SD}=45.7$; range: 0 to151.0).

The provider sample contained more females $(64 \% ; 4$ of 4 nurses and 5 of 10 physicians) than males, and consisted of 1 African-American, 1 Asian-American, and 12 Whites.

Categories of Appropriate Drinking Level. The categories that emerged from the theme of 'appropriate drinking level,' were: (1) stop completely; (2) cut down; (3) occasional drink is ok; (4) mixed/ambiguous messages and (5) did not routinely discuss alcohol. We do not know if any of the patients in our sample actually spoke with the providers in our sample, but we did find that at least one patient reported hearing each of the categories under this theme reported by the providers. The categories, along with illustrative quotations, are presented in the Table 1 . As can be observed from the content of the Table 1 , the degree of variation in advice about 'appropriate drinking level' was reported by both patient and provider samples.

Nine of the sixteen providers gave their HCV patients who were nonharmful drinkers advice to "stop completely," while only two advised patients, to "just cut down," and five reported telling patients that an "occasional drink was "ok." Eight of the providers reported only giving one message about level of alcohol consumption, whereas "ambiguous messages," the giving of multiple messages about alcohol consumption, were reported by four providers, all of which reported telling patients to "stop completely." In addition to this message, three of the four also reported telling patients that an occasional drink was 'ok', and one reported telling them to cut-down. For some patients, these ambiguous messages were even more confusing, as many of them came into contact with a number of healthcare providers in the course of their disease, who did not always deliver consistent messages about alcohol consumption. The nurse respondents in our study acknowledged that these "ambiguous messages" put patients in the difficult position of having to choose between a number of suggestions about alcohol consumption. Lastly, two providers recalled that alcohol use was "not routinely discussed in the patient-provider visit" unless the patient presented with symptoms or abnormal lab values.

There was also considerable variation in what different types of providers reported telling their $\mathrm{HCV}$ patients about alcohol consumption. The recommendation about alcohol consumption most often reported by the GI providers was to 'stop completely,' ( $N=8$ of 10 ) while IM providers were less consistent by telling their patients: an 'occasional drink was OK,' $(N=1$ of $5)$, to 'cut down on drinking' ( $N=2$ of 5), or to 'stop completely' $(N=2$ of 5$)$. Indeed, those patient respondents who reported hearing "stop completely" were more likely to have had their last medical visit before study participation at the GI clinic ( $N=$ 18 ) as opposed to the IM clinic $(N=9)$.

There was also a difference in the language providers used to advise their patients to reduce or abstain from alcohol. Most of the IM providers, in explaining to their patients about why it was important to reduce or abstain from alcohol, used 
Table 1. What Providers Say and What Patients Hear: Appropriate Drinking Level

\begin{tabular}{|c|c|c|}
\hline Themes & Provider respondents & Patient respondents \\
\hline $\begin{array}{l}\text { Stop } \\
\text { completely }\end{array}$ & $\begin{array}{l}\text { "Quit completely because we don't know what amount, } \\
\text { whether it is one glass of wine a month or one glass of wine a } \\
\text { day that causes this increased damage." (GI Physician } \\
\text { Interview 1) }\end{array}$ & $\begin{array}{l}\text { "Every doctor that I talked to is totally against it (alcohol). } \\
\text { Especially for someone with hepatitis because they said it was } \\
\text { a hundred times worse to drink than someone who doesn't } \\
\text { have hepatitis C." (Patient Interview 260) }\end{array}$ \\
\hline Cut down & $\begin{array}{l}\text { "I really can't say I run into that many difficulties with } \\
\text { nonharmful drinkers. I ask them to cut down, or ask them } \\
\text { to hold it for a month, a year, or until their treatment is over, } \\
\text { or whatever." (IM physician focus group) }\end{array}$ & $\begin{array}{l}\text { "My doctor told me that my liver was in such good shape, so just } \\
\text { cut down on your drinking." (Patient Interview 6) }\end{array}$ \\
\hline $\begin{array}{l}\text { Occasional } \\
\text { drink is ok }\end{array}$ & $\begin{array}{l}\text { "I actually tell them, sure special occasions, weddings, holidays, } \\
\text { things like that, are OK, but not to make it a habit." (GI } \\
\text { Physician Interview } 3 \text { ). }\end{array}$ & $\begin{array}{l}\text { "One of my doctors says you can drink very moderately. You can } \\
\text { have a little wine with your dinner. You can have a beer once in } \\
\text { a while. My doctor did tell me that. But I didn't believe him. I } \\
\text { figured abstaining was the best way to go." (Patient Focus } \\
\text { Group 3) }\end{array}$ \\
\hline $\begin{array}{l}\text { Mixed/ } \\
\text { ambiguous } \\
\text { messages }\end{array}$ & $\begin{array}{l}\text { "I tell them that my suggestion is that they become a tea-totaler! } \\
\text { That's usually followed immediately by 'You mean I can never } \\
\text { have a drink?' So I tell them that's it's probably unlikely that it } \\
\text { would cause a great deal of harm if they had an occasional } \\
\text { drink, like at Christmas, but I can't swear to that." (GI Physician } \\
\text { Interview 6) }\end{array}$ & $\begin{array}{l}\text { "Well, after I was diagnosed with hepatitis C, my doctors let me } \\
\text { know the consequences of using alcohol. But you know, then } \\
\text { again, they told me a glass of wine every now and then with } \\
\text { your dinner wouldn't hurt." (Patient Focus Group 1) }\end{array}$ \\
\hline $\begin{array}{l}\text { Never } \\
\text { routinely } \\
\text { discussed } \\
\text { alcohol }\end{array}$ & $\begin{array}{l}\text { "If a patient comes in with symptoms or abnormal labs, then it } \\
\text { comes up as part of the discussion, but on just a routine basis, } \\
\text { talking about cutting down on alcohol or even the adverse } \\
\text { effects of alcohol, takes a pretty minimal role." (IM Physician } \\
\text { Focus Group) }\end{array}$ & $\begin{array}{l}\text { Interviewer: Doctors suggest any changes to lifestyle? Resp: “Just } \\
\text { check my blood every } 90 \text { days." Interviewer: "Did doctors or } \\
\text { nurses talk to you about drinking alcohol?" Resp: “No" (Patient } \\
\text { Interview 151) }\end{array}$ \\
\hline
\end{tabular}

technical or medical language "I tell them that it (alcohol) speeds up the progression of the fibrosis and cirrhosis," (IM Physician Focus Group) while GI physicians and nurses generally used simple analogies or "everyday language" to drive the message about drinking home:

"I try to make analogies and they seem to understand that better if you compare the body to like a car or like a washing machine. So I tell them that the liver is the thing that detoxifies everything you take in, be it a food, medication, alcohol, whatever it is, and it cleans out those things from your body. But if your washing machine belt is not working well and you have $\mathrm{HCV}$, that would be like a liver that's not functioning well and doesn't have that cleaning ability." (Nurse Focus Group)

Indeed, the use of a simple analogy such as "it's like throwing gas on the fire" (when you drink with a diagnosis of HCV) by a provider (GI Physician Interview 3) was acknowledged by one patient as "putting it in a good simple way" (Patient Interview 111). The use of "medical language" by providers has long been regarded as a source of problems for patients, while "everyday language" has been shown to promote better understanding. ${ }^{27}$

\section{CONCLUSIONS}

A main purpose of medical communication is promoting the exchange of information between the provider and the patient. ${ }^{28,29}$ As can be seen in the Figure 1, both patients and providers in IM settings face a number of challenges that may contribute to poor communication and incorrect information about alcohol consumption in the context of HCV.
The patients utilize many sources of health information including: providers, family/friends, media (television, health magazines, general magazines, newspapers, radio), and increasingly the Internet (via websites, list-serves, online support groups, chat rooms, instant messaging, and email). ${ }^{30-32}$ Out of all these sources, patients view physicians as the most trustworthy. ${ }^{30}$ However, our research shows that information patients receive from physicians and other providers may not always be consistent. One provider alone or multiple providers (internist and specialist) can give different/conflicting messages.

Providers in these settings face additional challenges. Primary care providers not only administer preventive and uncomplicated care (i.e., urinary/respiratory infections) to their patients, they also provide longitudinal care to patients with chronic conditions, such as heart disease, hypertension, diabetes, arthritis, and depression. ${ }^{33}$ Many times these providers are required to address multiple medical problems ${ }^{34}$ leaving only 1-min out of a 20-min visit for discussing treatment and planning. ${ }^{35}$

These challenges, in addition to ambiguous guidelines and research findings about HCVand alcohol consumption, ${ }^{6,7}$ little formal training about $\mathrm{HCV}$, and caring for fewer symptomatic HCV patients than GI providers, may lay the groundwork for ambiguous alcohol recommendations to $\mathrm{HCV}$ patients seen in IM clinics. In addition, studies on advice about alcohol consumption in IM settings have focused only on "at-risk" or "heavy drinkers" 36 those "screening positive for alcohol misuse" ${ }^{\text {77,38 }}$ and those who have undergone alcohol treatment recently. ${ }^{39}$

$\mathrm{HCV}$ is a major public health issue with just over four million Americans currently infected, ${ }^{40}$ and projected medical costs for the years 2010 to 2019 of almost \$11 billion, and societal costs of $\$ 54$ billion due to years of life lost under the age of $65 .{ }^{41}$ Our study is significant in that it is the first study to explore the range of themes and topics touched on in the patient-provider encounter surrounding the issue of HCV and 


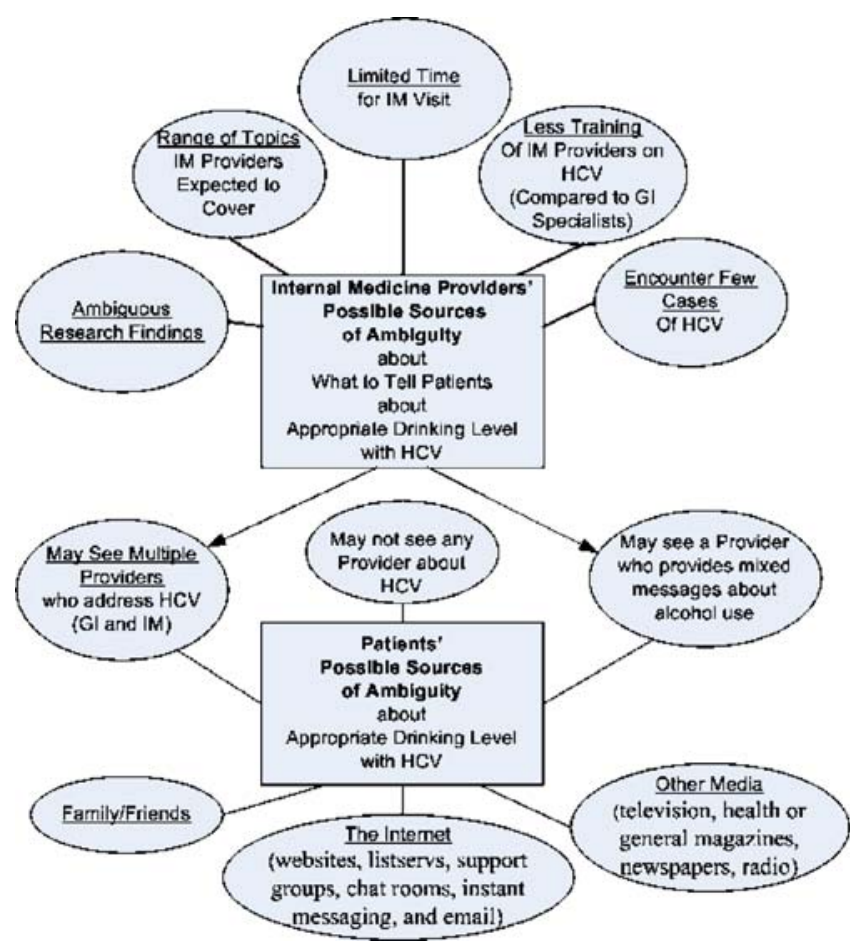

Figure 1. Provider and patient possible sources of ambiguity about appropriate drinking level with HCV.

alcohol consumption among nonharmful drinkers. In this population, receiving multiple or ambiguous messages from a single provider or across providers may encourage or contribute to the "tailoring" of advice about alcohol consumption reported on by Stoller et al.,13 and encourage patients to pick the advice that best fits their current situation. Agreement and consistent presentation as to the best message to present to nonharmful drinkers seen in IM settings would be a step in the right direction toward helping $\mathrm{HCV}$ patients make informed decisions about their health and may decrease the personal and societal costs associated with this disease. IM Departments can increase provider knowledge about $\mathrm{HCV}$ and alcohol consumption by providing more education and training on $\mathrm{HCV}$ through grand rounds presentations, CME courses, and consultations with GI providers.

Limitations of the Study and Future Research. This study did not use exact pairs of patients and providers nor did we seek recollections from specific visits. This was an exploratory qualitative study and the use of such methods would not have served our goals of (1) learning what providers believe that they generally tell HCV patients who are nonharmful drinkers about alcohol, and (2) what these patients believe that they have heard from doctors and nurses during healthrelated clinic visits. While the number of providers and patients is relatively small, the study focused on intensely interviewing and analyzing the results of a group of providers and patients who varied in race/ethnicity and levels of alcohol intake. This level of intensity was crucial to assure that all possible facets of patient-provider communication were explored and covered, in an area (alcohol advice for $\mathrm{HCV}$ patients in a real clinical setting) where there is little prior work to build upon.

Future research should focus on validating our findings by audio or video-taping the patient-provider encounter among a larger sample of nonharmful drinkers with $\mathrm{HCV}$ and following them longitudinally to investigate the effects of provider messages about alcohol consumption on patients' drinking behaviors. Most importantly, researchers, clinicians, and policy makers need to come to some consensus on guidelines for physicians and other healthcare professionals on what to tell nonharmful drinkers with HCV about alcohol consumption.

Acknowledgement: This research was supported by a grant from the National Institute of Alcohol Abuse and Alcoholism NIH Grant \# 1 RO1 AA13302, Neal V. Dawson, M.D., PI. An earlier version of the paper was presented as a poster at the Society for Medical Decision Making, 27th Annual Meeting, San Francisco, CA, October 21-24, 2005. The title of the presentation was "Mixed Messages: What Healthcare Providers Say and What Patients Hear About Alcohol Consumption and Hepatitis C."

Conflict of Interest: None disclosed.

Corresponding Author: Neal V. Dawson, MD; Department of Medicine, Case Western Reserve University School of Medicine and Center for Health Care Research and Policy, MetroHealth Medical Center, 2500 MetroHealth Drive, Cleveland, $\mathrm{OH}$ 44109-1998, USA (e-mail: nvd@case.edu). 


\section{REFERENCES}

1. Zeller JL, Lynm C, Glass RM. JAMA patient page. Hepatitis C. JAMA 2007;297:768.

2. National Institutes of Health. National Institutes of Health Consensus Development Conference statement: management of hepatitis C: 2002 June 10-12, 2002. Hepatology. 2002;365 Suppl. 1S3-20.

3. Poynard T, Bedossa P, Opolon P. Natural history of liver fibrosis progression in patients with chronic hepatitis C. Lancet. 1997; 349:825-32.

4. Hezode C, Lonjon I, Roudot-Thoraval F, Pawlotsky JM, Zafrani ES, Dhumeaux D. Impact of moderate alcohol consumption on histological activity and fibrosis in patients with chronic hepatitis $\mathrm{C}$, and specific influence of steatosis: a prospective study. Aliment Pharmacol Ther 2003; 17:1031-7

5. Pessione F, Degos F, Macellin P, et al. Effect of alcohol consumption on serum hepatitis $\mathrm{C}$ virus RNA and histological lesions in chronic hepatitis C. Hepatology. 1998;27:1717-22.

6. Westin J, Lagging LM, Spak F, et al. Moderate alcohol intake increases fibrosis progression in untreated patients with hepatitis $\mathrm{C}$ virus infection. J Viral Hepatitis. 2002;9:235-41.

7. Ostapowicz G, Watson KJ, Locarnini SA, Desmond PV. Role of alcohol in the progression of liver disease caused by hepatitis $\mathrm{C}$ virus infection. Hepatology. 1998;27:1730-5.

8. Tabone M, Sidoli L, Laudi C, et al. Alcohol abstinence does not offset the strong negative effect of lifetime alcohol consumption on the outcome of interferon therapy. J Viral Hepatitis. 2002;9:288-94.

9. Strasser SI, Watson KJ, Lee CS, et al. Risk factors and predictors of outcome in an Australian cohort with hepatitis C virus infection. Med $\mathrm{J}$ Aust. 1995; 162:355-8.

10. Selvey L, Sririjalingam M, Crawford D, et al. Alcohol does not play a significant role in promoting cirrhosis in chronic hepatitis C: analysis of 102 patients [Abstract]. Hepatology. 1994;20:254A.

11. Survey of Hepatitis C Patient Needs. The Epi-Log Newsletter. 2005;45(6) Accessed online at: http://www.metrokc.gov/health/epilog/vol4506. htm. Accessed on August 20, 2007.

12. Safdar K, Schiff E. Alcohol and Hepatitis C. Semin Liver Dis 2003;24:305-15.

13. Stoller EP, Hund AJ, Webster NJ, et al. Alcohol consumption within the context of hepatitis C: a qualitative study of non-problematic drinkers. Alcohol Alcohol. 2006;41:546-52.

14. Babor TF, de la Fuente J, Saunders J, Grant M. AUDIT. The Alcohol Use Disorders Identification Test. Guidelines for use in primary health care. Geneva, Switzerland: World Health Organization; 1992.

15. Bohn MJ, Babor TF, Kranzler HR. The Alcohol Use Disorders Identification Test (AUDIT): validation of a screening instrument for use in medical setting. J Stud Alcohol. 1995;56:423-32.

16. Ewing JA. Detecting alcoholism: the CAGE Questionnaire. JAMA 1984;252:1905-7.

17. Strauss A, Corbin J. Basics of Qualitative Research: Techniques and Procedures for Developing Grounded Theory, 2 edn. Thousand Oaks, CA Sage Publications; 1998.

18. Morse J. Qualitative Health Research. Thousand Oaks, CA: Sage Publications; 2002.

19. Krueger R. Focus Groups: A Practical Guide for Applied Research Thousand Oaks, CA: Sage Publications; 1994
20. Rubin H, Rubin I. Qualitative Interviewing: The Art of Hearing Data. Thousand Oaks, CA: Sage Publications; 1995.

21. Weiss R. Learning from Strangers: The Art and Method of Qualitative Interviews. NY, NY: Free Press; 1995.

22. Ezzy D. Qualitative Analysis: Practice and Innovations. New York: Routledge; 2003.

23. Strauss A, Corbin J. Basics of Qualitative Research: Techniques and Procedures for Developing Grounded Theory, 2 edn. Thousand Oaks, CA: Sage Publications; 1998.

24. Esterberg K. Qualitative Methods in Social Research. Boston, MA: McGraw Hill; 2002.

25. QSR International. 2003. Available at: http://www.qsr.com.au/. Accessed August 20, 2007

26. Marshall C, Rossman G. Designing Qualitative Research, 3 edn. Thousand Oaks, CA: Sage Publications; 1999:154

27. Bourhis RY, Roth S, MacQueen G. Communication in the hospital setting: a survey of medical and everyday language use amongst patients, nurses and doctors. Social Science and Medicine. 1998;28: 339-46.

28. Roter D, Hall J, Katz N. Patient-physician communication: a descriptive summary of the literature. Patient Educ Couns. 1988;12:99-119.

29. Inui TS, Carter WB. Problems and prospects for health services research on provider-patient communication. Med Care. 1985;23:521-38.

30. Hesse BW, Nelson DE, Kreps GL, et al. Trust and sources of health information. Arch Intern Med. 2005;165:2618-24.

31. Cotten S, Gupta SS. Characteristics of online and offline health information seekers and factors that discriminate between them. Social Science and Medicine. 2004;59:1795-806.

32. Grandinetti DA. Doctors and the Web: help your patients surf the Net safely. Med Econ. 2000;63:28-34.

33. Bodenheimer T. Primary care-will it survive. N Engl J Med. 2006;355:861-4

34. Beasley JW, Hankey TH, Erickson R, et al. How many problems do family physicians manage at each encounter? A WReN Study. Annals of Family Medicine. 2004;2:405-10.

35. Waitzkin H. Doctor-patient communication. Clinical implications of social scientific research. JAMA. 1984;252:2441

36. Bradley KA, Epler AJ, Bush K, et al. Alcohol-related discussions during general medicine appointments of male VA patients who screen positive for at-risk drinking. J Gen Intern Med. 2002;17:315-26.

37. McCormick KA, Cochran NE, Back AL, Merrill JO, Williams EC, Bradley KA. How primary care providers talk to patients about alcohol: a qualitative study. J Gen Intern Med. 2006;21:966-72.

38. Aalto M, Seppa Kaija. Usefulness, length and content of alcohol-related discussions in primary health care: the exit poll survey. Alcohol Alcohol. 2004;39:532-5.

39. Burman ML, Kivlahan D, Buchbinder M, et al. Alcohol-related advice for veterans affairs primary care patients: who gets it? Who gives it. J Stud Alcohol. 2004;65:621-30.

40. Armstrong GL, Wasley A, Simard EP, McGuillan GM, Kuhnert WL, Alter MJ. The prevalence of hepatitis C virus in the United States, 1999 through 2002. Ann Intern Med. 2006;144:705-15.

41. Wong JB, McQuillan GM, McHutchison JG, Poynard T. Estimating future hepatitis C morbidity, mortality, and costs in the United States. Am J Public Health. 2000;90:1562-9. 